\title{
Uncertainties in a Baltic Sea Food-Web Model Reveal Challenges for Future Projections
}

\author{
Susa Niiranen, Thorsten Blenckner, Olle Hjerne, \\ Maciej T. Tomczak
}

\begin{abstract}
Models that can project ecosystem dynamics under changing environmental conditions are in high demand. The application of such models, however, requires model validation together with analyses of model uncertainties, which are both often overlooked. We carried out a simplified model uncertainty and sensitivity analysis on an Ecopath with Ecosim food-web model of the Baltic Proper (BaltProWeb) and found the model sensitive to both variations in the input data of pre-identified key groups and environmental forcing. Model uncertainties grew particularly high in future climate change scenarios. For example, cod fishery recommendations that resulted in viable stocks in the original model failed after data uncertainties were introduced. In addition, addressing the trophic control dynamics produced by the food-web model proved as a useful tool for both model validation, and for studying the food-web function. These results indicate that presenting model uncertainties is necessary to alleviate ecological surprises in marine ecosystem management.
\end{abstract}

Keywords Food-web - Baltic Sea - Uncertainty · Model sensitivity $\cdot$ Ecopath with Ecosim .

Ecosystem-based management

\section{INTRODUCTION}

The challenge of global climate change in combination with the growing needs for marine resources such as fish (Jackson et al. 2001) have created a high demand for ecological models that can produce information relevant

Electronic supplementary material The online version of this article (doi:10.1007/s13280-012-0324-z) contains supplementary material, which is available to authorized users. for ecosystem-based management. While these models can be powerful tools, they are always simplifications of reality, with several unknowns and caveats (Hastings 1990; Li and $\mathrm{Wu}$ 2006). Yet model uncertainties are not standardly addressed in often complex ecosystem models (Planque et al. 2011).

Ecological models are subject to uncertainty in the model structure and input data (Beck 1987; Li and Wu 2006; Turley and Ford 2009). The structural model uncertainty is rather seldom studied, and in food-web models this has mainly been addressed by comparing models with different levels of complexity (Vichi et al. 2003; Brown et al. 2010). Uncertainties originating from the input data are studied more often, and several model uncertainty and sensitivity analysis methods are available. The Monte Carlo random parameter search procedure (Waller et al. 2003) and the Extended Fourier Amplitude Sensitivity Test (Saltelli et al. 1999) are examples of comprehensive stochastic methods. However, these require a vast number of repeated model runs and resource limitation may prevent their implementation on complex models. As an alternative, meta-modeling approaches, capable of estimating error propagation from data to model uncertainty with reduced computational cost exist (Scavia et al. 1981a, b; Ratto et al. 2007). More recently, also Bayesian uncertainty analyses have been applied to ecosystem models (Mäntyniemi et al. 2009).

In the ECOSUPPORT project (Meier et al. 2012), we simulate for the first time how the combined changes in future climate, fishery, and nutrient loads may affect the Baltic Sea food-web dynamics, using the open Baltic Sea Ecopath with Ecosim food-web model BaltProWeb (Tomczak et al. 2012, but see Lindegren et al. [2010] for fishery and climate effects on the future of the Baltic cod). To ensure the usability of such projections, information 
about model capabilities and limitations, i.e., model uncertainty, is needed. Previously, only few uncertainty or sensitivity studies have been applied on Ecopath with Ecosim (EwE) models (Aydin et al. 2005; Bundy 2005; Coll et al. 2008; Walters et al. 2008; Rochette et al. 2009; Morissette et al. 2010), regardless that EwE is a worldwide popular approach to simulate aquatic food-webs (Fulton 2010). EwE has some built-in model uncertainty routines. For example, probability estimates of all input data can be estimated, based on qualitative information about data reliability (pedigree tool). This information can then be used to build a mass-balance Ecopath model (Christensen and Walters 2004). Also, a Monte Carlo routine is available for testing Ecosim model uncertainty and sensitivity to parameterization, or to optimize the Ecopath input for improved Ecosim model fit (Christensen et al. 2008). However, at the time of this study these tools were not fully functional with models that accommodate age-structured groups (multi-stanza in EwE).

In this study, a simplified model uncertainty and sensitivity analysis was applied on the BaltProWeb model. We use the term "model uncertainty" to describe the variation in the model results caused by the uncertainties, or variation, in the model input data and "model sensitivity" to describe the relative effect that a known change in a single input/forcing has on the model results. First, we identified the groups that the model is most sensitive to, defined uncertainty proxies for their model input biomasses and then studied resulting model uncertainty together with model sensitivity. Furthermore, the potential uncertainty under different future conditions was tested with different fishery and climate scenarios. In addition, we addressed model sensitivity to changes in environmental forcing, and studied the combinations of trophic control that were modeled as a result of model fitting to data.

\section{MATERIALS AND METHODS}

\section{Study Area}

The semi-enclosed Baltic Sea is one of the world's largest brackish water ecosystems (Leppäranta and Myrberg 2009). It has a low biodiversity (Ojaveer et al. 2010) and, due to low salinity and large spatial and temporal gradients in environmental conditions, many Baltic Sea organism groups live close to their physiological limits (Remane 1934). The food-web model used in this study is parameterized to the Baltic proper conditions, i.e., the central basin of the Baltic Sea. Baltic proper food-web dynamics are well studied and in the past, fishery, climate, and high nutrient inputs have caused ecosystem-wide changes, i.e., regime shifts in the system (Österblom et al. 2007;
Möllmann et al. 2008). The most recent shift took place in the late 1980s. It was initiated by changes in climate and fishery and resulted in low cod Gadus morhua stock, highly increased abundance of planktivore sprat Sprattus sprattus and a changed zooplankton composition (Casini et al. 2008; Möllmann et al. 2008, 2009).

\section{Modeling Approach}

The BaltProWeb food-web model (Tomczak et al. 2012) builds on EwE, which is a widely used software package developed for modeling trophic flows within aquatic ecosystems (Christensen and Walters 2004, Christensen et al. 2008). The model has 22 functional groups (described in Tomczak et al. 2012) and comprises a mass-balance model (Ecopath), balanced for the year 1974, and a time-dynamic (1974-2006) simulation model (Ecosim).

A mass-balance Ecopath equation, which describes the production of a group $(i)$ eaten by predators $(j$, where $j=1$, $\ldots, n)$ and/or exploited by fishery, forms the initial conditions for an EwE model (Polovina 1984; Christensen and Pauly 1992) (Eq. 1, excluding migration)

$$
\begin{aligned}
B_{i} \cdot\left(\frac{P}{B}\right)_{i}= & \sum_{j=1}^{n}\left(\frac{C}{B}\right)_{j} \cdot B_{j} \cdot \operatorname{diet}_{i j}+F_{i} \cdot B_{i} \\
& +M 0_{i} \cdot B_{i}+B A_{i},
\end{aligned}
$$

where $B_{i}$ is the biomass, $(P / B)_{i}$ the annual production per biomass ratio, $F_{i}$ is the fishing mortality, $M 0_{i}$ the predation independent natural mortality rate, and $B A_{i}$ the biomass accumulation of prey $i .(C / B)_{j}$ is the annual consumption per biomass ratio, $B_{j}$ is the biomass, and $\operatorname{diet}_{i j}$ the proportion of $i$ in the diet of predator $j$. The initial parameterization of $B_{i}$ is addressed in this uncertainty and sensitivity analysis.

In the time-dynamic Ecosim, biomass changes are estimated by coupled differential equations (Eq. 2) that are derived from Eq. 1

$\frac{\mathrm{d} B_{i}}{\mathrm{~d} t}=g_{i} \sum_{j} C_{j i}-\sum_{j} C_{i j}-\left(F_{i}+M 0_{i}\right) \cdot B_{i}$,

where $g_{i}$ is the net growth efficiency and $\sum_{j} C_{j i}$ the total food consumption of $i . \sum_{j} C_{i j}$ is the total biomass of $i$ predated.

The description of trophic interactions between functional groups is based on a foraging arena theory according to which each prey population is split into a component that is vulnerable and a component that is invulnerable to predation (Walters et al. 1997; Ahrens et al. 2012). The rate at which the prey can move between these two components determines the predation rates on a particular prey population and is in Ecosim determined by a vulnerability $(v)$ parameter. If $v$ is high $(>2)$, the prey biomass vulnerable to predation is, rapidly after being depleted, replaced from the 
invulnerable component and predation control is top-down. If $v$ is low $(<2)$, the replacement of the vulnerable biomass is slow and the predation control is bottom-up. The total amount of prey $(i)$ consumed by predator $(j)$ is estimated by Eq. 3 (in simplified form)

$C_{i j}=\frac{a_{i j} \cdot v_{i j} \cdot B_{i} \cdot B_{j}}{2 v_{i j}+a_{i j} \cdot B_{j}}$,

where $C_{i j}$ is the total consumption of $i$ by $j, a_{i j}$ the effective search rate for $i$ by $j$, and $v_{i j}$ vulnerability of $i$ to predation by $j . B_{i}$ and $B_{j}$ as in Eq. 1 .

An automated Ecosim calibration procedure was used to test for different combinations of $v$ s for 20 predator-prey relationships that the model is most sensitive to, while all other $v$ s were set for the default value 2, i.e., mixed predation control. The combination of $v$ s that resulted in the best model, i.e., the lowest sum of squares (SS) of model deviation from the observations for the 1974-2006, was chosen. The model was driven by fishing mortality of cod, herring, and sprat, environmental forcing (introduced below) and fish reproduction time-series. The same calibration data as in Tomczak et al. (2012) were used.

\section{Simplified Model Uncertainty and Sensitivity Analysis}

The model uncertainty and sensitivity analysis was carried out in several steps and is presented in Fig. 1.

\section{Key Groups and Variation in Their Input Biomass Data}

Step 1. First, the key groups, i.e., the groups that have the largest effects on the ecosystem (here the model output), were identified using the relative total impact (RTI) index of the EwE software (version 6). Our definition of key groups does not exclude groups with higher biomass, and hence the requirements for actual keystone species, as discussed, e.g., in Power et al. (1996), may be compromised. RTI is calculated from the mixed trophic impact (MTI) (Eqs. 4 and 5, Leontief 1951; Ulanowicz and Puccia 1990; Christensen et al. 2008), which describes the direct and indirect effects that a very small increase in the biomass of impacting group $(j)$ would have on the biomass of impacted group ( $i$ ) and is estimated for each pair of functional groups

$$
\begin{gathered}
\mathrm{RTI}=\sqrt{\sum_{i \neq j}^{n} \mathrm{MTI}_{j i}^{2}}, \\
\mathrm{MTI}_{j i}=\mathrm{DC}_{j i}-\mathrm{FC}_{i j},
\end{gathered}
$$

where the diet composition term $\mathrm{DC}_{j i}$ describes how much $i$ contributes to the diet of $j$. The term $\mathrm{FC}_{i j}$ describes the proportion of predation on $i$ that is due to $j$. Pre-identification of some of the most important model parameters allows targeting the analysis on the groups that the model is most sensitive to and has previously been used in the sensitivity and uncertainty analysis of other food-web modeling approaches (e.g. Ciavatta et al. 2009).

Step 2. Here, the level of uncertainty in the Ecopath biomass $(B)$ input of key groups was estimated. The coefficients of variation $(\mathrm{CV})$ of biomass data (Table 1) were used as uncertainty proxies, and the possible input ranges for the five highest ranking key groups were calculated $\left(B_{1974} \pm 2 \times C V \times B_{1974}\right)$. The $C V$ values for all zooplankton and macrozoobenthos were calculated from the annual biomass averages for 1974-1978 to be consistent with the way how the original Ecopath input $B$ were calculated, i.e., the 5-year (1974-1978) medians of annually averaged biomass data. For sprat and cod, both the CV values and the biomass data are from the ICES Baltic Sea fish stock assessment report (ICES 2008).

\section{Model Uncertainty Caused by the Variation in Input Biomass Data}

Step 3. The time-dynamic Ecosim model uncertainty related to the input biomass $(B)$ was tested by replacing the Ecopath $B$ of key groups with the upper and lower biomass limits from the potential biomass ranges (step 2). To entangle how sensitive the model was to changes in individual key groups, the biomass changes were made one-ata-time, and the original biomass input values of all other groups were left unchanged (Hamby 1994). In cases where Ecopath was not mass-balanced with the new Ecopath $B$ value, the lowest/highest value that enabled mass-balance was used. Ecosim was recalibrated after each biomass change, using the same forcing and reference data as in the original model. This resulted in ten new calibrated Ecosim models (models 1-10). The group (mysids and macrozoobenthos) and aggregated group (phytoplankton, zooplankton, clupeids (herring + sprat), cod (2-3 years + adult)) specific fits, i.e., SS, for the ten new models are presented as the percentage change from the corresponding fits in the original model. These results were further normalized to describe the effect of $10 \%$ change in the original Ecopath $B$ of each key group.

Trophic control was studied in detail in selected predator-prey relationships and compared between the models 1-10 and the original model. We assumed top-down control when there was a positive relationship between the predator biomass and the amount of prey consumed $\left(C_{i j}\right.$ in Eq. 3) and bottom-up control when there was a positive relationship between the prey biomass and the amount of prey consumed. The type, strength, and statistical 


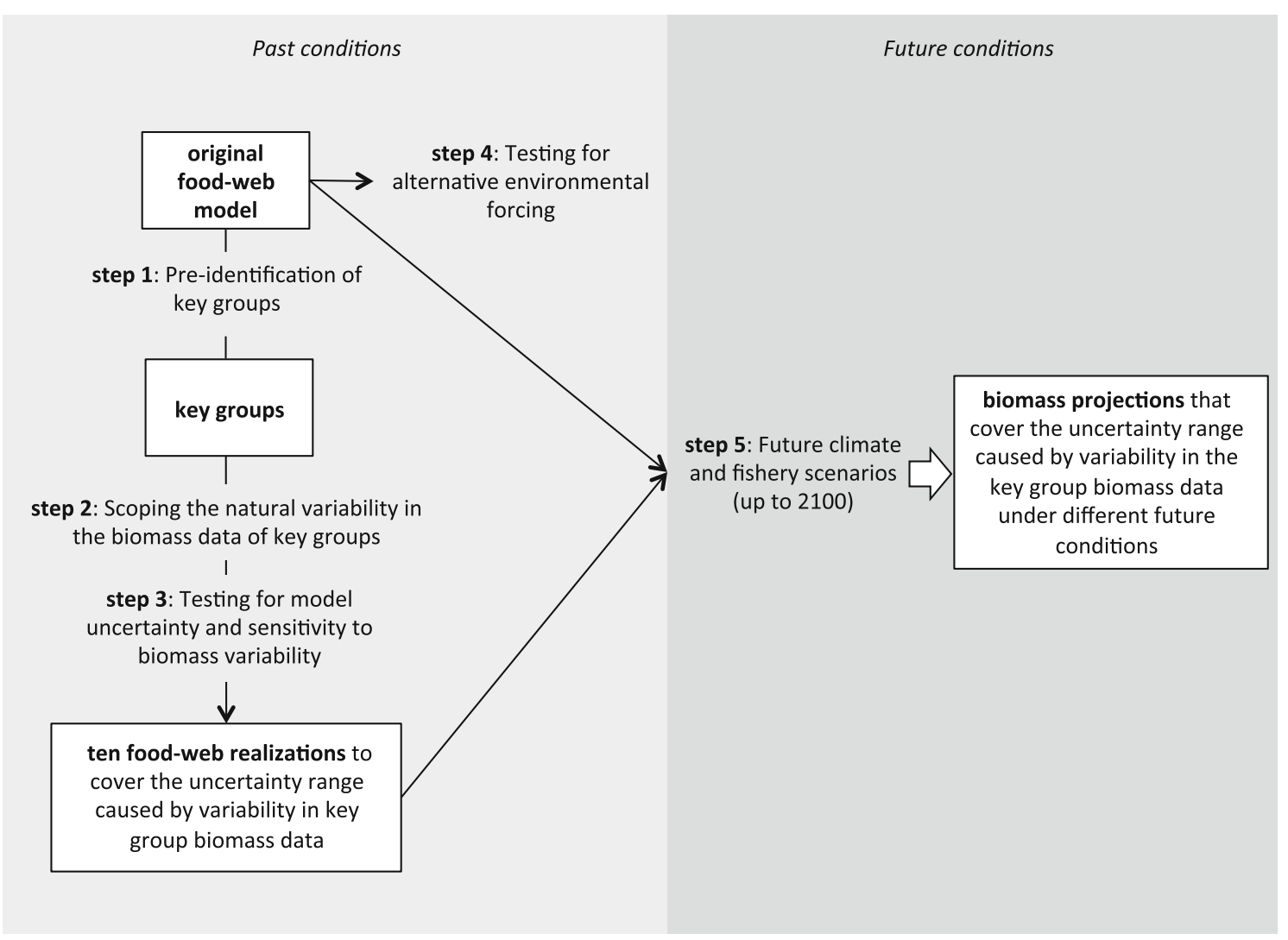

Fig. 1 A conceptual diagram of the simplified model uncertainty and sensitivity analysis method used. Steps 1-5 represent different stages of the analysis and are presented in detail in "Materials and Methods"

significance of such control were analyzed using linear regression analysis. In the BaltProWeb model, trophic control is realized as the result of model fitting to data, as often is the case with EwE models. Hence, studying the plausibility of trophic control mechanisms modeled is an important method of model validation.

\section{Alternative Environmental Forcing of the Past}

Step 4. In the BaltProWeb model, direct environmental forcing is applied on six functional groups. Cod reproductive volume (RV), i.e., the volume of water with suitable salinity ( $>11 \mathrm{psu})$ and oxygen $\left(\mathrm{O}_{2},>2 \mathrm{ml} \mathrm{l}^{-1}\right)$ conditions for cod reproduction (Plikshs et al. 1993), and August sea surface $(0-10 \mathrm{~m})$ temperature force cod and sprat reproduction, respectively. Spring (March-May) upper watercolumn $(0-50 \mathrm{~m})$ temperature drives changes in the prey vulnerability ( $v_{i j}$ in Eq. 3 ) to Acartia spp. and Temora longicornis predation. Hypoxic area $\left(\mathrm{O}_{2}<2 \mathrm{ml}^{-1}\right)$ is assigned a negative effect on prey vulnerability to predation by macrozoobenthos and mysids. For more detailed descriptions, see Tomczak et al. (2012).

In the original model, forcing functions were obtained by normalizing the observed environmental time-series with the 1974 value. In this study, we replaced every original forcing with time-series of similar shape, but increased/decreased the annual deviation from the year 1974 value by 10 and $20 \%$ (Fig. 2a). Only one forcing time-series was changed at a time and the model was recalibrated after each change.

\section{How Uncertain Are Climate and Fishery-Driven Future Food-Web Projections Based on Changes in Key Group Biomasses?}

Step 5. The original model and the models 1-10 were used to study how the assumed uncertainties in the input biomasses of key groups may translate in model uncertainties in future (2006-2100) projections. Three future scenarios were run with all models: (1) cod business as usual fishery scenario (BAU, fishing mortality $(F)=1.08$ ), (2) cod recovery plan fishery scenario ( $\mathrm{F} 03, F=0.3$ as adopted by the EU Council [2007]), and (3) cod recovery plan combined with climate change $(\mathrm{F} 03+C)$, i.e., A1B1 emission scenario (IPCC 2007). The $F$ for cod in the BAU scenario is the average $F$ for in 1996-2005 (ICES 2008). In all scenarios, the future $F$ for sprat and herring represents the calculated average of $F$ for 1996-2005 (0.36 and 0.34, 
Table 1 Key functional groups with ecosystem structuring role as identified by the Relative Trophic Impact (RTI) index; also CV values for input biomass $(B)$ data, original Ecopath $B$ input values, and lower and upper $B$ limits (as suggested by the $\mathrm{CV}$ values calculated from the biomass data)

\begin{tabular}{|c|c|c|c|c|c|}
\hline Group & RTI-index & $\mathrm{CV}$ & $\begin{array}{l}B \text { lower limit } \\
\left(\mathrm{t} \mathrm{km}^{-2}\right)\end{array}$ & $\begin{array}{l}\text { Ecopath } B \\
\left(\mathrm{t} \mathrm{km}^{-2}\right)\end{array}$ & $\begin{array}{l}B \text { upper limit } \\
\left(\mathrm{t} \mathrm{km}^{-2}\right)\end{array}$ \\
\hline Cod 2, 3 & 1 & 0.22 & $0.57(0.98)$ & 1.02 & 1.46 \\
\hline Adult sprat & 0.91 & 0.64 & $0(3.22)$ & 4.21 & $9.61(4.39)$ \\
\hline Macrozoobenthos & 0.71 & 0.95 & $0(2.55)$ & 27.30 & $79.17(35.86)$ \\
\hline P. acuspes & 0.69 & 0.19 & 2.72 & 4.39 & $6.058(5.26)$ \\
\hline Other mesozooplankton & 0.63 & 0.73 & $0(0.31)$ & 4.00 & $9.84(4.11)$ \\
\hline Adult cod & 0.50 & - & - & 0.49 & - \\
\hline Mysids & 0.49 & - & - & 2.04 & - \\
\hline Herring $0,1,2$ & 0.49 & - & - & 3.97 & - \\
\hline T. longicornis & 0.46 & - & - & 1.90 & - \\
\hline Other phytoplankton & 0.45 & - & - & 4.50 & - \\
\hline
\end{tabular}

The value in the brackets is the upper/lower $B$ limit that was able to balance Ecopath, in case the $B$ values suggested by CVs were incapable of doing that
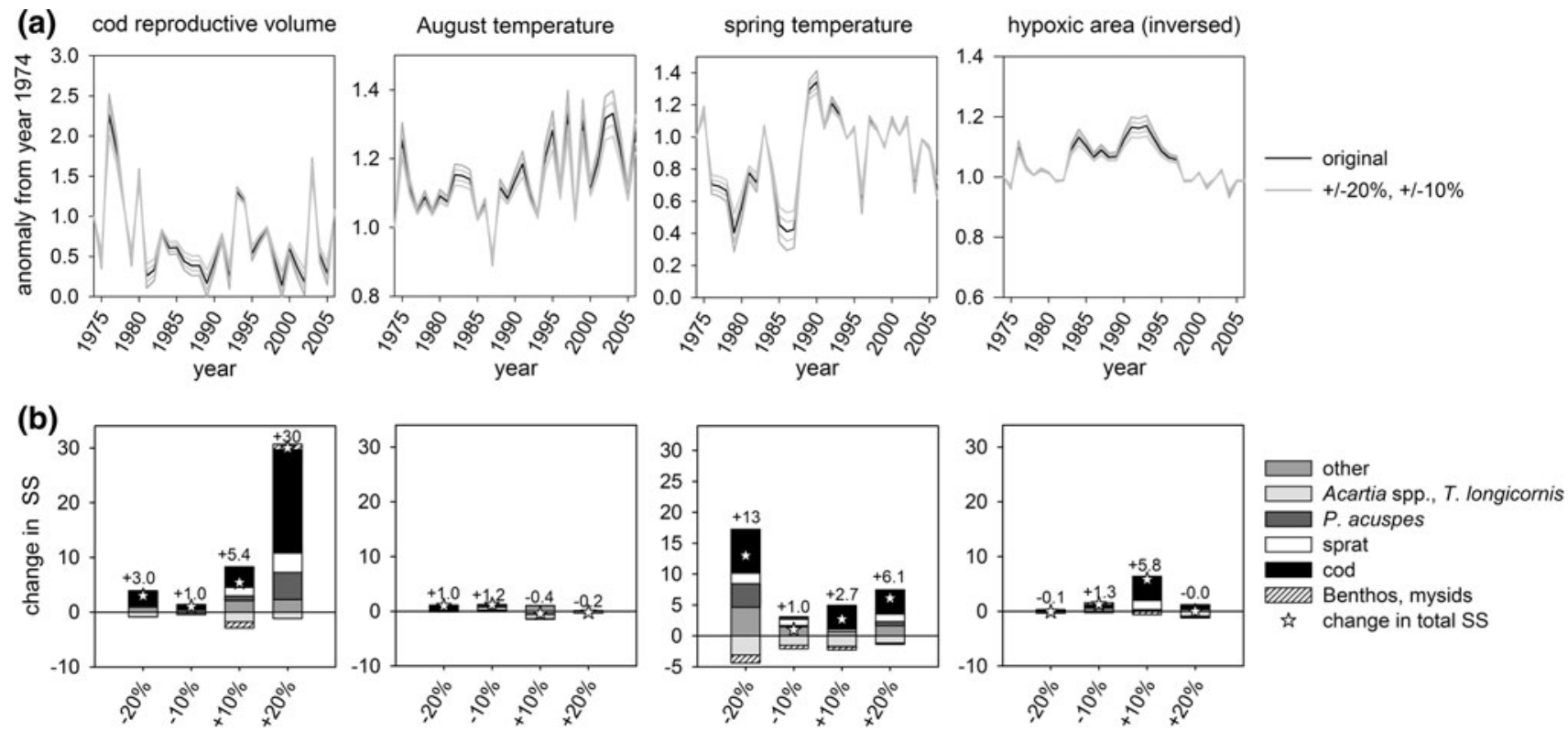

Fig. 2 a Alternative climate forcing functions used in the model calibration, $\mathbf{b}$ deviations in the total model fits (i.e., sum of squares (SS), indicated by numbers above bars) and group-specific fits from the original model caused by one-at-a-time changes, i.e., \pm 10 and

respectively). The environmental time-series used in the $\mathrm{F} 03+C$ scenario are simulations from the biogeochemical model, Baltic Sea Long Term large-Scale Eutrophication Model (BALTSEM; Gustafsson 2000, 2003). In our analysis, the type of climate scenario was not so important, as the main aim was to demonstrate the importance of climate forcing in general for the food-web model simulations. In both "only-fishery" scenarios, the future (2006-2100) environmental/climate forcing was calculated as the average in the last 5 years of the model calibration period (2002-2006) (Fig. S1, Electronic supplementary material). $\pm 20 \%$ deviation, in environmental forcing [panels from left: changes in cod reproductive volume, August temperature, spring temperature, and hypoxic area (inverted)]

\section{RESULTS}

\section{Key Groups and Variation in Their Input Biomass Data}

Steps 1 and 2. The BaltProWeb model is, in decreasing order, most sensitive to biomass changes in 2-3 years old cod (from now on referred as small cod), adult sprat, macrozoobenthos, Pseudocalanus acuspes, and other mesozooplankton (excluding P. acuspes, Acartia spp. and T. longicornis) (Table 1). The biomass CV values for the 
above-mentioned key groups ranged from 0.19 to 0.95 . The highest $\mathrm{CV}$ value was calculated for macrozoobenthos, a group for which we have access to scarce data with high spatial variability. The lowest biomass CV was obtained for $P$. acuspes. For all key groups, the biomass range that resulted in a mass-balanced Ecopath model was smaller than the range indicated by the $\mathrm{CV}$ values.

\section{Model Uncertainty Caused by the Variation in Input Biomass Data}

Step 3. The differences in the total model fit (measured in SS) between the ten new recalibrated models and the original model are between $-0.1 \%$ (model 7 ) and $28.5 \%$ (model 5) (Table 2, including model abbreviations). In most groups, excluding phytoplankton, the highest relative change in the model fit was caused by changes in the small cod input biomass. On average, clupeids and cod were the groups most affected by decreases and increases in the biomasses of other key groups $(6.2 \%$ and $5.0 \%$ per $10 \%$ change, respectively). The model fit of cod worsened particularly when the macrozoobenthos biomass was decreased, but was also clearly affected by changes in the lower trophic level groups such as $P$. acuspes and other mesozooplankton. The fit of clupeids was primarily worsened by changes, especially increase, in the cod biomass.

The biomass dynamics (1974-2006) of cod, sprat, and $P$. acuspes, which are considered among the most important components regarding the Baltic Proper food-web function (e.g., Casini et al. 2009), were studied in all ten new models in relation to the original model (Fig. 3). Changes in the initial conditions of 1974, i.e., Ecopath $B$, produced a wide range of biomass estimates in all three groups. Some of the largest deviations from the original model were caused by the large variations in the other mesozooplankton and macrozoobenthos biomasses (see also Table 2 for the percentage changes in the total model fit (SS) in models 5 and 9).

Table 2 Changes in the model fit (sum of squares (SS)) per $10 \%$ change in the Ecopath biomass $(B)$ input for key groups

\begin{tabular}{|c|c|c|c|c|c|c|c|c|c|c|c|c|}
\hline Group & $\begin{array}{l}\text { Original } \\
\text { SS }\end{array}$ & $\begin{array}{l}\text { Model } 1 \\
\text { Cod } \\
\text { Low (-) }\end{array}$ & $\begin{array}{l}\text { Model } 2 \\
\text { Cod } \\
\text { High (+) }\end{array}$ & $\begin{array}{l}\text { Model } 3 \\
\text { Sprat } \\
\text { Low (-) }\end{array}$ & $\begin{array}{l}\text { Model } 4 \\
\text { Sprat } \\
\text { High (+) }\end{array}$ & $\begin{array}{l}\text { Model } 5 \\
\text { mzb } \\
\text { Low (-) }\end{array}$ & $\begin{array}{l}\text { Model } 6 \\
\text { mzb } \\
\text { High (+) }\end{array}$ & $\begin{array}{l}\text { Model } 7 \\
\text { Pseudo } \\
\text { Low (-) }\end{array}$ & $\begin{array}{l}\text { Model } 8 \\
\text { Pseudo } \\
\text { High (+) }\end{array}$ & $\begin{array}{l}\text { Model } 9 \\
\text { ozpl } \\
\text { Low (-) }\end{array}$ & $\begin{array}{l}\text { Model } 10 \\
\text { ozpl } \\
\text { High (+) }\end{array}$ & $\mathrm{I} \Delta \mathrm{I}$ mean \\
\hline Phytoplankton & 4.01 & 1.91 & 0.00 & -2.33 & -0.64 & -0.91 & 0.03 & -1.25 & -0.98 & -0.87 & 0.00 & 0.89 \\
\hline Zooplankton & 24.01 & 2.23 & -7.54 & -1.04 & -0.94 & 0.01 & 0.06 & -1.18 & -2.01 & 0.59 & -0.02 & 1.18 \\
\hline Clupeids & 21.95 & 8.48 & 44.15 & 15.77 & 0.66 & 1.08 & -0.01 & 3.16 & 1.75 & 3.54 & 0.00 & 6.22 \\
\hline Cod & 11.48 & 49.98 & 71.08 & 2.74 & 6.93 & 18.85 & 0.68 & -3.55 & 7.85 & 8.68 & 0.18 & 4.95 \\
\hline Benthos & 14.16 & 3.42 & 9.54 & 2.88 & 0.54 & -1.46 & 0.33 & 0.39 & 0.67 & 0.77 & 0.01 & 1.82 \\
\hline Mysids & 34.18 & -4.85 & -2.46 & -0.95 & 0.37 & -0.16 & 0.03 & -1.02 & -0.67 & -0.02 & 0.00 & 1.05 \\
\hline Total SS & 143.21 & 148.94 & 156.71 & 160.38 & 147.55 & 184.09 & 145.29 & 143.03 & 150.49 & 177.87 & 143.58 & \\
\hline$\%$ Change & & 4.00 & 9.43 & 11.99 & 3.03 & 28.54 & 1.45 & -0.13 & 5.08 & 24.20 & 0.25 & \\
\hline
\end{tabular}

The change in the SS is the percentage change from the group-specific (some are aggregated groups) SS in the original model. The total SS and \% change in the total SS describe the realized values for models 1-10 (i.e., not recalculated per $10 \%$ change). Note: the total SS also includes the $\mathrm{SS}$ of catch and the mean changes $(\mathrm{I} \Delta \mathrm{I})$ include only effects from the biomass changes of other key groups

Pseudo, Pseudocalanus acuspes; ozpl, other mesozooplankton; mzb, macrozoobenthos; +, stands for testing the upper; -, the lower $B$ limit
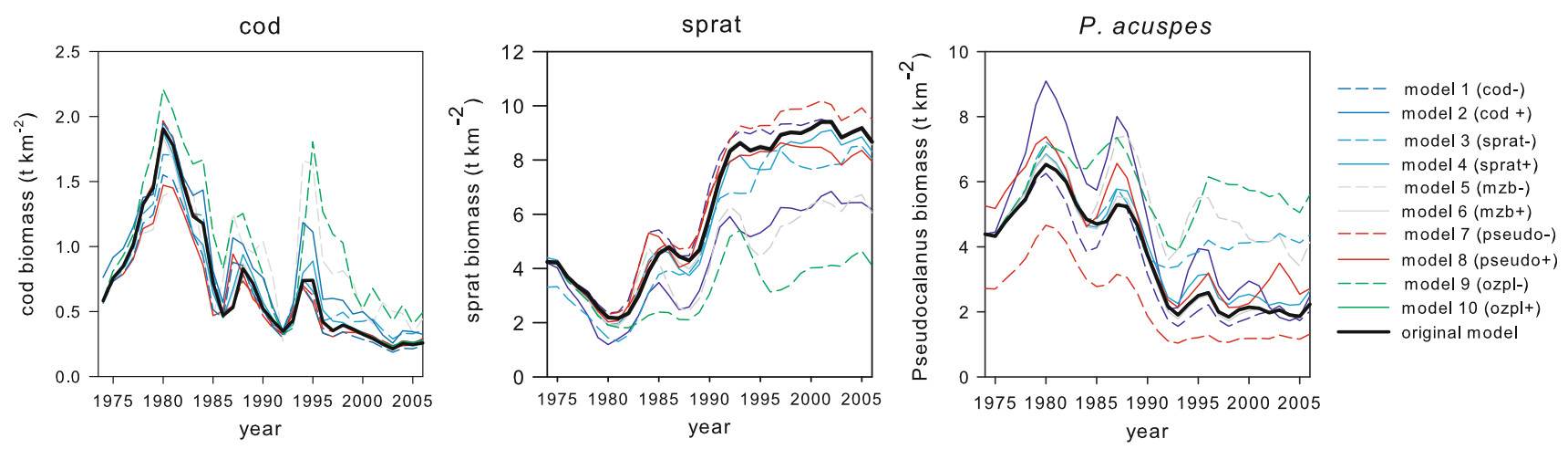

Fig. 3 Cod, sprat, and P. acuspes biomasses in the original model and models 1-10 (model abbreviations as in Table 2) 


\section{Changes in Trophic Control}

The overall trophic control between cod (adult + small) and sprat (adult + juvenile) was mixed, both bottom-up and top-down, in all models (Fig. 4, first column). Adult cod consumption on adult sprat had a noisy, but statistically significant, signal of top-down control in models 5 and 9 (Fig. 4a, second panel). In the original model and models 2 and 3, this relationship was strongly bottom-up controlled (Fig. 4b, second panel; see also vulnerabilities). The predation of juvenile sprat by small cod was top-down controlled in most models (Fig. 4a, third panel). A significant negative biomass relationship was detected between adult cod and adult sprat (Fig. 4c, second panel), as well as cod (adult + small) and all sprat in all models (Fig. 4c, first panel). Between small cod and juvenile sprat, a significant negative biomass relationship was found in the original model and models 2 and 3 (Fig. 4c, third panel). The adult sprat consumption on $P$. acuspes is primarily top-down controlled, and this relationship is statistically significant, in all models (Fig. 4a, fourth panel). In model 3, the topdown control saturates after the sprat biomass reaches high values (approx. above $4 \mathrm{t} \mathrm{km}^{-2}$ ). The dominant trend of the biomass relationship between sprat and $P$. acuspes is negative in all models (Fig. 4c, fourth panel), but in model 3 this negative relationship dissolves at lower $P$. acuspes abundances. The slopes and statistical significance of all relationships are shown in Table S1, Electronic supplementary material. All in all, the overall trophic control differed most from the original model in models $2,3,5$, and 9.

\section{Alternative Environmental Forcing of the Past}

Step 4. In general, changes in the environmental forcing variables decreased the overall model fit in comparison to the original model, with the exception of some negligible improvements (Fig. 2b). The overall model fit was most affected by changes in the cod reproductive volume (RV) and spring temperature, and in both cases the model fit decreased with increased deviation from the original environmental forcing (Fig. 2b, first and third panel). The largest decrease in the model fit ( +30 in SS) was caused by a $20 \%$ increase in the cod RV deviation. When altering the spring temperature, the highest decrease in the model fit $(+13$ in SS) was caused by the $20 \%$ decrease in the deviation. Total model performance was least affected by changes in August temperature, which forced sprat reproduction. Also, for August temperature and hypoxic area the change in the total model fit was not always linearly related to the magnitude of change in the forcing variables (Fig. 2b, second and fourth panels). For example, a $10 \%$ deviation decrease in the hypoxic area forcing worsened the model fit by 1.3 in SS, while a $20 \%$ decrease lead to a slightly improved model fit $(-0.1$ in SS), compared to the original model. Across model simulations, forced by different environmental settings, the changes triggered in the cod (small + adult) biomass mostly contributed to changes in the total model fit. The fits of cod and Acartia spp./T. longicornis were most affected by changes in the environmental time-series they were directly forced with, i.e., cod RV and spring temperature. The fits of sprat and $P$. acuspes were more affected by indirect effects caused by changes in the trophic interactions. The fit of Acartia sp./T. longicornis was improved as a result of many changes in the environmental forcing, even if the total model SS increased. The fits of macrozoobenthos and mysids were overall very little affected.

\section{How Uncertain Are Climate and Fishery-Driven Future Food-Web Projections?}

Step 5. The future biomass estimates of cod increased as a response to the decreased fishing pressure (from BAU to F03) in the original model and most of the ten models (Fig. 5a, columns BAU and F03). However, even in the low fishing pressure scenario (F03), the future cod biomasses were as high as in the 1980s only in model 9. In all scenarios, the majority of the biomass projections of the ten new models were close to those of the original model. However, the total range of biomass estimates was rather large across all groups and scenarios being particularly high when future climate change was accounted for (Fig. 5a-c, column $\mathrm{F} 03+C$ ). For example, very high biomasses of cod, sprat, and P. acuspes were estimated by some models, while others projected biomasses close to extinction. In the scenarios with no climate change the cod biomasses projected by the original model were amongst the lowest across models. In the climate change scenario, some other models projected clearly lower future biomasses for cod than the original model.

\section{DISCUSSION}

\section{Model Uncertainty Caused by Variations in the Input Biomass Data}

The BaltProWeb food-web model was most sensitive to changes in the biomasses of cod and sprat. However, the largest variations in the simulations were caused by the relatively large uncertainty in the biomass data of macrozoobenthos and other mesozooplankton. Hence, particular effort should be aimed to the data analysis and parameterization of these groups. Earlier publications have concluded that the Ecopath with Ecosim models are very 
(a) $\operatorname{cod}(2,3+a d)-$ sprat (juv + ad)

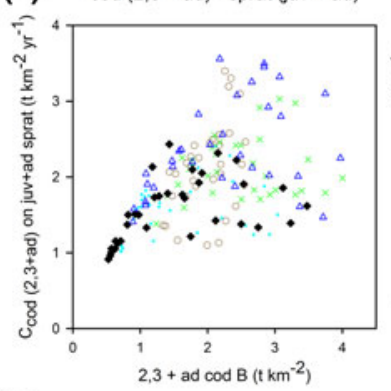

(b)

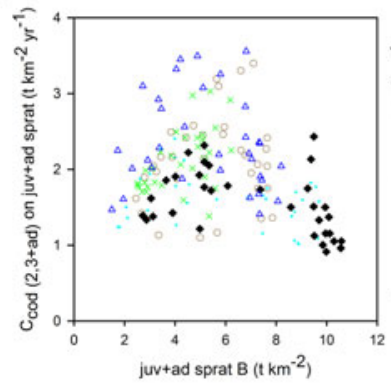

(c)

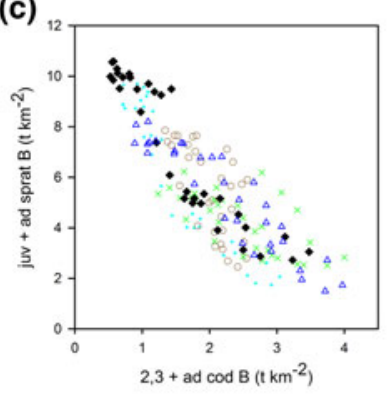

$\operatorname{cod}(\mathrm{ad})$ - sprat (ad)
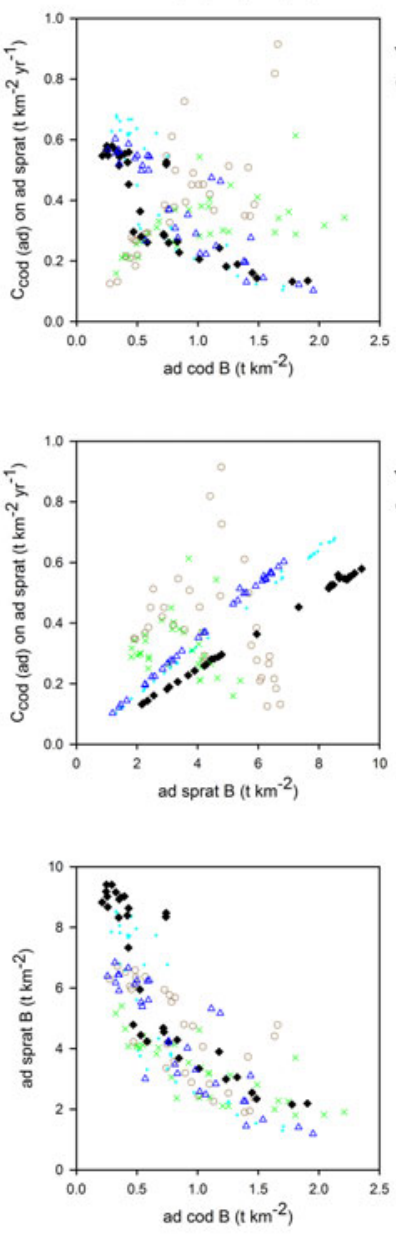

$\triangle \quad \mathrm{v}=1$

$\mathrm{v}=1$

$v=3.8$

$\mathrm{v}=1$

Fig. 4 a Top-down trophic control, b bottom-up trophic control, and c relationship between the predator and prey biomasses of cod (small $(2,3)+$ adult (ad)) and sprat (juvenile (juv) + adult), adult cod and adult sprat, small cod and juvenile sprat, and adult sprat and $P$. acuspes in the original model and models 2, 3, 5, and 9. The

sensitive to changes in vulnerability settings that define the type of trophic control for each predator-prey relationship (e.g., Christensen and Walters 2004; Walters et al. 2008; Brown et al. 2010). We used these vulnerability values ( $v$ in Eq. 3) as free variables (Petersen 2000). This means that the types of trophic control in the predator-prey relationships that the model is most sensitive to (either bottomup or top-down) were automatically estimated to best fit the calibration data. By this approach we were able to define what combinations of trophic control were realized in each model and how possible differences affected model performance. The initial intent was to use the trophic control information to rule out some models as mechanistically

$\operatorname{cod}(2,3)$ - sprat (juv)
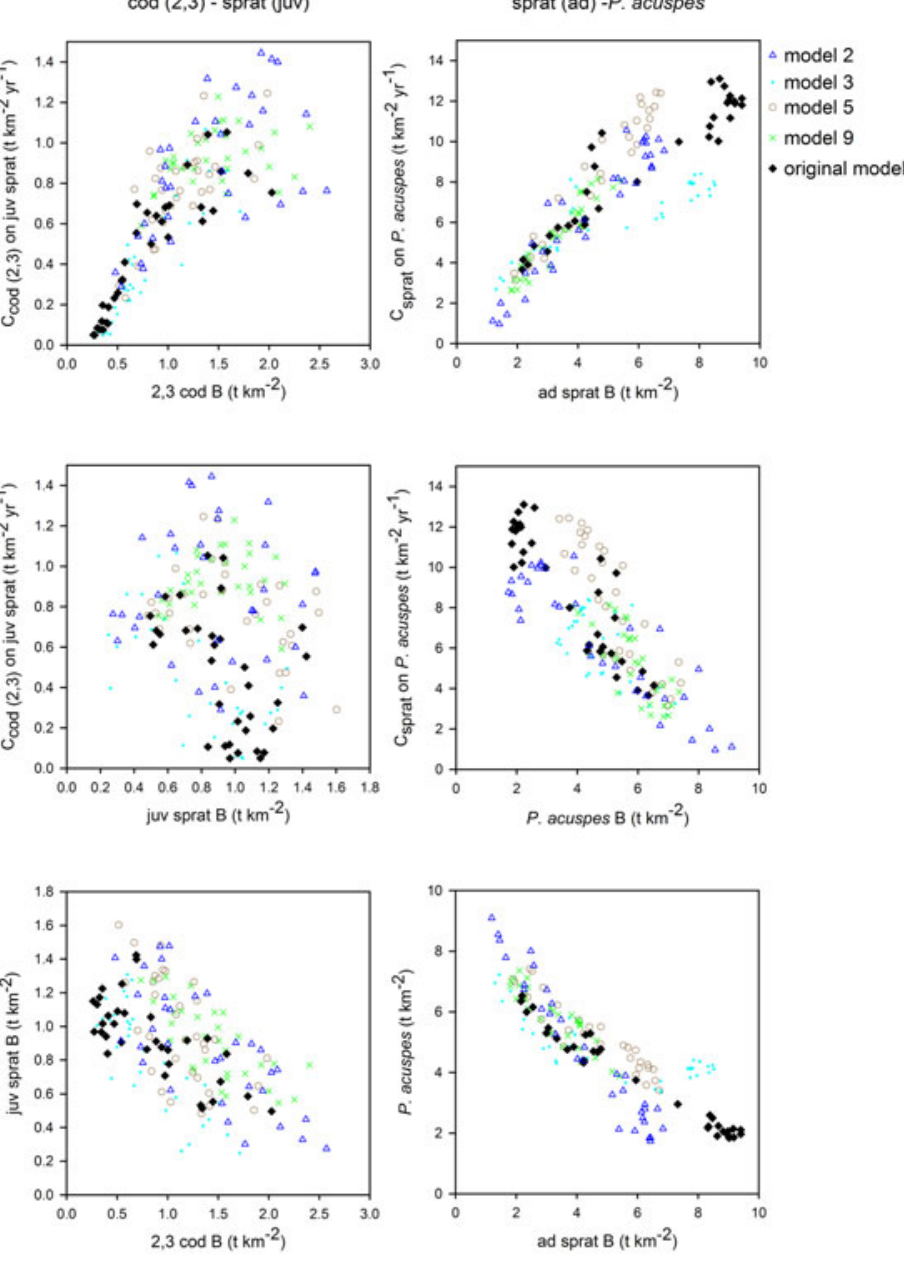

A $\quad \begin{aligned} \mathrm{v} & =4.3 \\ \mathrm{v} & =4.6 \\ \mathrm{v} & =2 \\ \mathrm{v} & =2 \\ \mathrm{v} & =2.3\end{aligned}$

$$
\begin{aligned}
& \quad v>1000 \\
& v=2 \\
& \quad v>1000 \\
& \times \quad v>1000 \\
& \quad v>1000
\end{aligned}
$$

vulnerability $(v)$ values for each predator-prey relationship and model are presented at the bottom of the graph. Note that cod (small + adult) and sprat (juvenile + adult) are aggregated groups and hence the $v$ values for this predator-prey relationship are not presented $(B=$ biomass $)$

unrealistic, but in the end we were unable to exclude any of the ten new models as being implausible. Consequently, results from all models were considered in this uncertainty and sensitivity analysis and their potential implications for model application addressed.

Our approach had some limitations that may have resulted in the underestimation of model uncertainty. The Ecopath requirement for mass-balance constrained the testing to smaller biomass ranges than indicated by the $\mathrm{CV}$ values. Also, only extreme values (i.e., the highest/lowest of the range) were tested for and changes were induced one-at-a-time, instead of changing several parameters simultaneously. Monte Carlo random sampling methods 

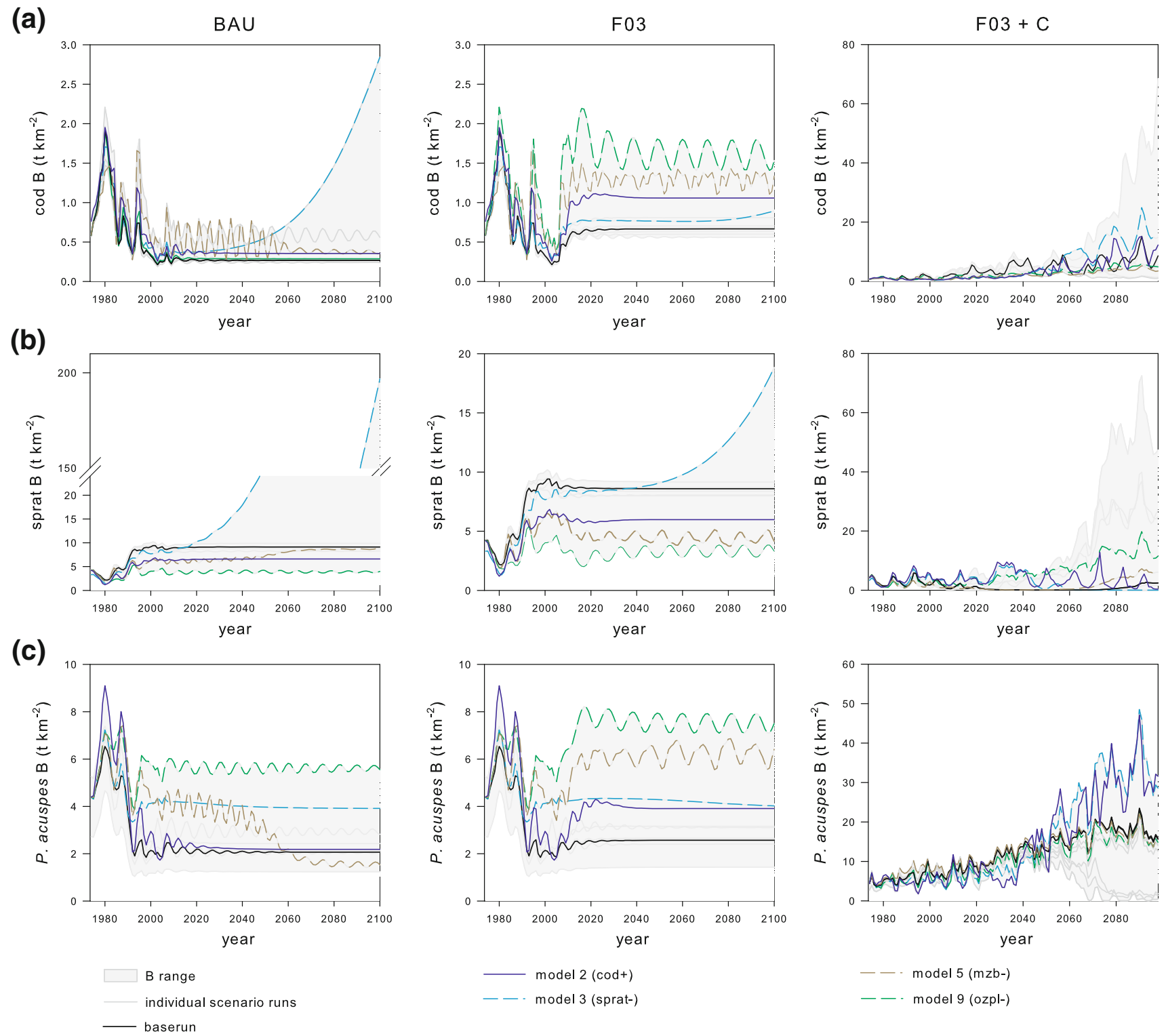

Fig. 5 The simulated biomasses of a adult cod, b adult sprat, and c P. acuspes in the BAU, F03, and F03 + $C$ future scenarios (see Fig. S1, Electronic supplementary material for model abbreviations, $B=$ biomass). Color coding of the different models as in Fig. 4

that are commonly used to test for model sensitivity (Turley and Ford 2009), would have allowed testing for simultaneous random changes in input parameters. A Monte Carlo routine is included in the Ecopath with Ecosim, but is currently incapable to handle multi-stanza, i.e., age-structured, groups and could therefore not be applied in this study.

\section{Food-Web Function}

Previous studies (Casini et al. 2009; Möllmann et al. 2009) add confidence to our results from the RTI analysis (step 1) that indicated cod, sprat, and $P$. acuspes as having important roles in the open Central Baltic Sea food-web. In addition, macrozoobenthos has been described as an important food source for cod, especially during the beginning of the modeled time period (Uzars 1994) and the other mesozooplankton group includes cladocerans that are important summer prey for clupeids (Flinkman et al. 1992; Möllmann et al. 2004; Casini et al. 2009).

Earlier, Libralato et al. (2006) have shown that the Ecopath MTI matrix (Eq. 5), corresponds well with the response of Ecosim model estimates. Our study that uses the relative trophic impact (RTI, Eq. 4), also based on the 
MTI, agrees with their results. For example, both the RTI and the Ecosim model sensitivity analysis (steps 3 and 4 ) imply that cod is the most important food-web structuring group in the Baltic Proper. In contrast to some previous studies (Harvey 2003; Casini et al. 2009; Möllmann et al. 2009), however, our results do not readily support the hypothesis that changes in the adult cod biomass directly act as the foremost pelagic ecosystem structuring mechanism. Most of our models, including the original, indicate bottom-up control between sprat and adult cod (Fig. 4). Yet in all models the small cod controls the biomass development of both juvenile and adult sprat resulting in a negative biomass relationship between adult cod and sprat. If these dynamics were mechanistically true, young cod may, under certain food-limited conditions, be capable of controlling the growth of its own stock by limiting the resources of adult cod. This would also suggest that, irrespective of the high sprat abundances since the early 1990s, adult cod were on average close to the carrying capacity concerning their prey adult sprat in 1974-2006. Earlier, the sprat availability as cod prey has been questioned, e.g., by Neuenfeldt and Beyer (2006). However, the age/stage specific cod-sprat dynamics indicated by the models have not been observed in previous studies and need to be further tested. In models 5 and 9 , the adult cod consumption on adult sprat showed a mixed or weak topdown control, which coincides with the theory that a combination of top-down and bottom-up trophic control is a likely mechanism behind the past biomass relationship observed between the adult cod and sprat (Casini et al. 2009). However, for both of these models, the fit to the data was worse than that of the original model.

In most models, sprat controls the $P$. acuspes biomass, which is in agreement with the findings of Möllmann et al. (2009). The bottom-up, or mixed, control between sprat and adult cod in combination with the top-down control between sprat and the zooplankton $P$. acuspes would indicate that sprat is able to control both its prey and predators. Such control by an intermediate trophic level group, i.e., the wasp-waist control, has, for example, been described in the North Sea, where the fishery-induced changes have been suggested to control the herring biomass and cascade both to herring prey (zooplankton) and predators (seabirds) (Fauchald et al. 2011). Based on our results, the possibility for such a control in the Baltic Proper should be further studied.

The mixed trophic control, together with environmental forcing, resulted in somewhat noisy signals in the trophic control and the predator-prey biomass relationships across models, which illustrates the importance of multiple drivers in single predator-prey interactions. Further, the mismatches between the types of predation control and predator-prey biomass relationships (e.g., for the relationship adult cod-adult sprat in Fig. 4, second column) provides an example for challenges in using the relationship of measured biomasses alone as indicators of trophic control.

\section{Environmental Forcing}

Several studies recognize the importance of environmental conditions for the functioning of the Baltic Sea food-web (e.g., Alheit et al. 2005; Möllmann et al. 2008, Casini et al. 2009). In the BaltProWeb model, the environmental forcing was used as anomalies from the 1974 values without any weighting of the different time-series. Here, we altered the strength of environmental forcing (step 4) and noticed that the model fit was affected even by rather moderate changes (Fig. 2). More importantly, changes in some model simulations, were non-linear in relation to the changes in the environmental forcing. Such unpredictability in model behavior results from the differences in trophic control, concomitant of refitting the model with new environmental forcing. The relatively strong effect of some environmental forcing, particularly the cod reproductive volume and spring temperature, indicate that it is important to know the group-specific responses to unit changes in relevant environmental variables. However, if the automatic calibration routine of Ecosim is used, the estimation of trophic control, i.e., vulnerabilities, is affected by the environmental forcing functions applied and thereby the implementation of even well known predator-prey relationships can be challenging.

\section{Variations in Future Projections}

Simulations of the future biomasses vary largely between models 1-10 (step 5, Fig. 5). Some biomass estimates of different models did overlap between different scenarios resulting in similar results under different future conditions. In many cases, the models with the most different trophic control in the calibration period, in comparison to the original model, also resulted in the most extreme biomass estimates in the future scenarios. In the climate change scenarios the biomass estimates of, e.g., cod were extremely high in some models, while in other models cod was driven near extinction. The large differences in future model results demonstrate that simulations with rather similar model fits (max. $29 \%$ deviation from the original), but differences in trophic control, can lead to very different biomass projections. Hence, it is crucial to study the plausibility of model dynamics beyond the model fit. Here, for example we have studied the trophic control mechanisms in different models. Such an approach may also be the only validation method available in data poor systems, or for models that require large data quantities in model 
calibration. In EwE models, for example, all available data are often used in model calibration, leaving no independent data sets available for model validation purposes.

\section{Implications to Ecosystem Management}

Even if the BaltProWeb model is not primarily intended as a management tool, but for studying the food-web dynamics under different conditions, this study does illustrate the importance of accounting for the model uncertainties, in particular if such models are used for ecosystem management. The model was sensitive to both, the uncertainties in the input data and changes in the climate forcing. Some alternative model projections even indicated future extinctions of commercially important fish species under cod fishery management plan, which resulted in abundant fish stocks in the original model. Based on these results we would motivate for presenting also the alternative model projections, at least the extremes, caused by model uncertainties whenever ecosystem models are used in management. This would enable the decision makers to evaluate the potential future outcome early in cases where the observed biomasses start to follow an alternative model path, instead of the original or average trajectories, and allow them to adapt the management accordingly. In addition, presenting the model uncertainties provides information on the probability of certain ecosystem conditions. In our analysis, the pre-identification of the key groups allowed us to focus on a limited number of parameters causing model uncertainty and sensitivity. Using such simplified approaches may be one solution in the attempt to mainstream the application of model uncertainty studies, particularly if full uncertainty and sensitivity analyses are not feasible due to resource limitation. An aspect that our analysis has not focused on, and which is hardly touched upon in the ecosystem modeling work in general, is the possibility of extreme events, such as extreme summers or sudden introduction of invasive species, in the long-term projections of ecosystem dynamics. Together with other model uncertainties, these extreme events are one of the key questions when managing marine ecosystems in the face of global climate change.

Acknowledgments The research presented in this study is part of the project ECOSUPPORT (Advanced modelling tool for scenarios of the Baltic Sea ECOsystem to SUPPORT decision making) and has received funding from the European Community's Seventh Framework Programme (FP/2007-2013) under grant agreement no. 217246 made with BONUS, the joint Baltic Sea research and development programme. We thank Bärbel Müller-Karulis for her comments on the earlier version of the manuscript.

\section{REFERENCES}

Ahrens, R.N.M., C.J. Walters, and V. Christensen. 2012. Foraging arena theory. Fish and Fisheries 13: 41-59.

Alheit, J., C. Möllmann, J. Dutz, G. Kornilovs, P. Loewe, V. Mohrholz, and N. Wasmund. 2005. Synchronous ecological regime shifts in the central Baltic and the North Sea in the late 1980s. ICES Journal of Marine Science 62: 1205-1215.

Aydin, K.Y., G.A. McFarlane, J.R. King, B.A. Megrey, and K.W. Myers. 2005. Linking oceanic food webs to coastal production and growth rates of Pacific salmon (Oncorhynchus spp.) using models on three scales. Deep-Sea Research II 52: 757-780.

Beck, M.B. 1987. Water-quality modeling-A review of the analysis of uncertainty. Water Resources Research 23: 1393-1442.

Brown, C.J., E.A. Fulton, A.J. Hobday, R.J. Matear, H.P. Possingham, C. Bulman, V. Christensen, R.E. Forrest, et al. 2010. Effects of climate-driven primary production change on marine food webs: Implications for fisheries and conservation. Global Change Biology 16: 1194-1212.

Bundy, A. 2005. Structure and functioning of the eastern Scotian Shelf ecosystem before and after the collapse of groundfish stocks in the early 1990s. Canadian Journal of Fisheries and Aquatic Sciences 62: 1453-1473.

Casini, M., J. Hjelm, J.C. Molinero, J. Lovgren, M. Cardinale, V. Bartolino, A. Belgrano, and G. Kornilovs. 2009. Trophic cascades promote threshold-like shifts in pelagic marine ecosystems. Proceedings of the National Academy of Sciences of the United States of America 106: 197-202.

Casini, M., J. Lovgren, J. Hjelm, M. Cardinale, J.C. Molinero, and G. Kornilovs. 2008. Multi-level trophic cascades in a heavily exploited open marine ecosystem. Proceedings of the Royal Society B-Biological Sciences 275: 1793-1801.

Christensen, V., C.J. Walters, D. Pauly, and R. Forrest. 2008. Ecopath with Ecosim version 6. User Guide-November 2008. Lenfest Ocean Futures Project.

Christensen, V., and D. Pauly. 1992. ECOPATH-II-A software for balancing steady-state ecosystem models and calculating network characteristics. Ecological Modelling 61: 169-185.

Christensen, V., and C.J. Walters. 2004. Ecopath with Ecosim: Methods, capabilities and limitations. Ecological Modelling 172: 109-139.

Ciavatta, S., T. Lovato, M. Ratto, and R. Pastres. 2009. Global uncertainty and sensitivity analysis of a food-web bioaccumulation model. Environmental Toxicology and Chemistry 28: 718-732.

Coll, M., N. Bahamon, F. Sardà, I. Palomera, S. Tudela, and P. Suuronen. 2008. Improved trawl selectivity: Effects on the ecosystem in the South Catalan Sea (NW Mediterranean). Marine Ecology Progress Series 355: 131-147.

EC. 2007. Council Regulation (EC) No. 1098/2007.

Fauchald, P., H. Skov, M. Skern-Mauritzen, D. Johns, and T. Tveraa. 2011. Wasp-waist interactions in the North Sea ecosystem. PLoS ONE 6: e22729. doi:10.1371/journal.pone.0022729.

Flinkman, J., I. Vuorinen, and E. Aro. 1992. Planktivorous Baltic herring (Clupea harengus) prey selectively on reproducing copepods and cladocerans. Canadian Journal of Fisheries and Aquatic Sciences 49: 73-77.

Fulton, E.A. 2010. Approaches to end-to-end ecosystem models. Journal of Marine Systems 81: 171-183.

Gustafsson, B.G. 2000. Time-dependent modelling of the Baltic entrance area. 1. Quantification of circulation and residence times in the Kattegat and the straits of the Baltic sill. Estuaries 23: $231-252$. 
Gustafsson, B.G. 2003. A time-dependent coupled-basin model of the Baltic Sea. C47. Göteborg: Earth Sciences Centre, Göteborg University.

Hamby, D.M. 1994. A review of techniques for parameter sensitivity analysis of environmental models. Environmental Monitoring and Assessment 32: 135-154.

Harvey, C. 2003. An ecosystem model of food web and fisheries interactions in the Baltic Sea. ICES Journal of Marine Science 60: 939-950.

Hastings, A. 1990. Spatial heterogeneity and ecological models. Ecology 71: 426-428.

ICES. 2008. Report of the Baltic Fisheries Assessment Working Group (WGBFAS). ICES CM 2008/ACOM:06, ICES Headquarters, Copenhagen.

IPCC. 2007. TS.3 Methods and scenarios. Climate Change 2007: Working Group II: Impacts, Adaption and Vulnerability.

Jackson, J.B., M.X. Kirby, W.H. Berger, K.A. Bjorndal, L.W. Botsford, B.J. Bourque, R.H. Bradbury, R. Cooke, et al. 2001. Historical overfishing and the recent collapse of coastal ecosystems. Science 293: 629-637.

Leontief, W.W. 1951. The structure of the US economy, 2nd ed. New York: Oxford University Press.

Leppäranta, M., and K. Myrberg. 2009. Physical oceanography of the Baltic Sea. New York: Springer Praxis Books.

Li, H., and J. Wu. 2006. Uncertainty analysis in ecological studies. In Scaling and uncertainty analysis in ecology: Methods and applications, ed. J. Wu, K.B. Jones, H. Li, and O.I. Loucks, 45-66. New York: Springer.

Libralato, S., V. Christensen, and D. Pauly. 2006. A method for identifying keystone species in food web models. Ecological Modelling 195: 153-171.

Lindegren, M., C. Möllmann, A. Nielsen, K. Brander, B.R. MacKenzie, and N.C. Stenseth. 2010. Ecological forecasting under climate change: the case of Baltic cod. Proceedings of the Royal Society B-Biological sciences 277: 2121-2130.

Mäntyniemi, S., S. Kuikka, M. Rahikainen, L.T. Kell, and V. Kaitala. 2009. The value of information in fisheries management: North Sea herring as an example. ICES Journal of Marine Science 66: 2278-2283.

Meier, H.E.M., B. Müller-Karulis, H.C. Andersson, C. Dieterich, K. Eilola, B.G. Gustafsson, A. Höglund, R. Hordoir, et al. 2012. Impact of climate change on ecological quality indicators and biogeochemical fluxes in the Baltic Sea-A multi-model ensemble study. AMBIO. doi:10.1007/s13280-012-0320-3.

Möllmann, C., G. Kornilovs, M. Fetter, and F.W. Koster. 2004. Feeding ecology of central Baltic Sea herring and sprat. Journal of Fish Biology 65: 1563-1581.

Möllmann, C., B. Muller-Karulis, G. Kornilovs, and M.A. St John. 2008. Effects of climate and overfishing on zooplankton dynamics and ecosystem structure: Regime shifts, trophic cascade, and feedback loops in a simple ecosystem. ICES Journal of Marine Science 65: 302-310.

Möllmann, C., R. Diekmann, B. Muller-Karulis, G. Kornilovs, M. Plikshs, and P. Axe. 2009. Reorganization of a large marine ecosystem due to atmospheric and anthropogenic pressure: A discontinuous regime shift in the Central Baltic Sea. Global Change Biology 15: 1377-1393.

Morissette, L., K. Kaschner, and L.R. Gerber. 2010. Ecosystem models clarify the trophic role of whales off Northwest Africa. Marine Ecology-Progress Series 404: 289-302.

Neuenfeldt, S., and J.E. Beyer. 2006. Environmentally driven predator-prey overlaps determine the aggregate diet of the cod Gadus morhua in the Baltic Sea. Marine Ecology-Progress Series 310: 151-163.

Ojaveer, H., A. Jaanus, B.R. MacKenzie, G. Martin, S. Olenin, T. Radziejewska, I. Telesh, M.L. Zettler, et al. 2010. Status of biodiversity in the Baltic Sea. PLOS ONE 5: e12467. doi: 10.1371/journal.pone.0012467.

Österblom, H., S. Hansson, U. Larsson, O. Hjerne, F. Wulff, R. Elmgren, and C. Folke. 2007. Human-induced trophic cascades and ecological regime shifts in the Baltic Sea. Ecosystems 10: 877-889.

Petersen, A.C. 2000. Philosophy of climate science. Bulletin of the American Meteorological Society 81: 265-271.

Planque, B., E. Bellier, and C. Loots. 2011. Uncertainties in projecting spatial distributions of marine populations. ICES Journal of Marine Science 68: 1045-1050.

Plikshs, M., M. Kalejs, and G. Grauman. 1993. The influence of environmental conditions and spawning stock size on the year class strength of the Eastern Baltic cod. ICES CM 1993/J:22.

Polovina, J.J. 1984. Model of a coral-reef ecosystem.1. The Ecopath model and its application to French Frigate shoals. Coral Reefs 3: $1-11$.

Power, M.E., D. Tilman, J.A. Estes, B.A. Menge, W.J. Bond, L.S. Mills, G. Daily, J.C. Castilla, J. Lubchenco, and R.T. Paine. 1996. Challenges in the quest for keystones. BioScience 46: 609-620.

Ratto, M., A. Pagano, and P. Young. 2007. State dependent parameter metamodelling and sensitivity analysis. Computer Physics Communications 177: 863-876.

Remane, A. 1934. Die Brackenwasserfauna. Zoologischer Anzeige 7: $34-74$.

Rochette, S., J. Lobry, M. Lepage, and P. Boet. 2009. Dealing with uncertainty in qualitative models with a semi-quantitative approach based on simulations. Application to the Gironde estuarine food web (France). Ecological Modelling 220: 122-132.

Saltelli, A., S. Tarantola, and K.P.S. Chan. 1999. A quantitative model-independent method for global sensitivity analysis of model output. Technometrics 41: 39-56.

Scavia, D., R.P. Canale, W.F. Powers, and J.L. Moody. 1981a. Variance estimates for a dynamic eutrophication model of Saginaw Bay, Lake Huron. Water Resources Research 17: 1115-1124.

Scavia, D., W.F. Powers, R.P. Canale, and J.L. Moody. 1981b. Comparison of 1st-order error analysis and Monte-Carlo simulation in time-dependent lake eutrophication models. Water Resources Research 17: 1051-1059.

Tomczak, M.T., S. Niiranen, O. Hjerne, and T. Blenckner. 2012. Ecosystem flow dynamics in the Baltic Proper-Using a multitrophic dataset as a basis for food-web modelling. Ecological Modelling 230: 123-147.

Turley, M.C., and E.D. Ford. 2009. Definition and calculation of uncertainty in ecological process models. Ecological Modelling 220: 1968-1983.

Ulanowicz, R.E., and C.J. Puccia. 1990. Mixed trophic impacts in ecosystems. Coenoses 5: 7-16.

Uzars, D. 1994. Feeding of cod (Gadus morhua callarias L.) in the central Baltic in relation to environmental changes. ICES Marine Science Symposia 198: 612-623.

Vichi, M., W. May, and A. Navarra. 2003. Response of a complex ecosystem model of the northern Adriatic Sea to a regional climate change scenario. Climate Research 24: 141-158.

Waller, L.A., D. Smith, J.E. Childs, and L.A. Real. 2003. Monte Carlo assessments of goodness-of-fit for ecological simulation models. Ecological Modelling 164: 49-63.

Walters, C., V. Christensen, and D. Pauly. 1997. Structuring dynamic models of exploited ecosystems from trophic mass-balance assessments. Reviews in Fish Biology and Fisheries 7: 139-172.

Walters, C., S.J.D. Martell, V. Christensen, and B. Mahmoudi. 2008. An ecosim model for exploring Gulf of Mexico ecosystem management options: Implications of including multistanza lifehistory models for policy predictions. Bulletin of Marine Science 83: $251-271$. 


\section{AUTHOR BIOGRAPHIES}

Susa Niiranen $(\varangle)$ is a PhD candidate at the Baltic Nest Institute and the Department of Systems Ecology of the Stockholm University. Her research is mainly focused on the Baltic Sea food-web dynamics and their response to environmental change.

Address: Baltic Nest Institute, Stockholm Resilience Centre, Stockholm University, 10691 Stockholm, Sweden.

e-mail: susa.niiranen@stockholmresilience.su.se

Thorsten Blenckner is a senior scientist at the Baltic Nest Institute and the Department of Systems Ecology of the Stockholm University. His research interests include food-web dynamics, multiple stressor effects on ecosystems and climate change research.

Address: Baltic Nest Institute, Stockholm Resilience Centre, Stockholm University, 10691 Stockholm, Sweden.

e-mail: thorsten.blenckner@ stockholmresilience.su.se
Olle Hjerne is an associate professor at the Department of Systems Ecology at Stockholm University. His research is mainly focused on Baltic Sea food-web dynamics, spanning from eutrophication, fish and fisheries management to seals.

Address: Department of Systems Ecology, Stockholm University, 106

91 Stockholm, Sweden.

e-mail: olle@ecology.su.se

Maciej T. Tomczak is a researcher at Baltic Nest Institute, Stockholm University. His research concentrates on food-web and fisheries interactions, integrated ecosystems assessment and management of marine ecosystems.

Address: Baltic Nest Institute, Stockholm Resilience Centre, Stockholm University, 10691 Stockholm, Sweden.

e-mail: maciej.tomczak@stockholmresilience.su.se 